\title{
A Systematic Review of Self-Coping Strategies Used by University Students to Cope with Public Speaking Anxiety
}

\author{
Xue Ting Tee ${ }^{1}$, Tjin Ai Tan Joanna ${ }^{2} \&$ Wirawahida Kamarulzaman ${ }^{3}$ \\ ${ }^{1}$ Universiti Tunku Abdul Rahman, Kampar, Perak, Malaysia \\ ${ }^{2}$ Department of Languages and Linguistics, Universiti Tunku Abdul Rahman, Kampar, Perak, Malaysia \\ ${ }^{3}$ Department of Psychology and Counselling, Universiti Tunku Abdul Rahman, Kampar, Perak, Malaysia \\ Correspondence: Xue Ting Tee, Universiti Tunku Abdul Rahman, Jalan Universiti, Bandar Barat, 31900 Kampar, \\ Negeri Perak, Malaysia.
}

Received: August 7, 2020

doi: $10.5539 /$ elt.v13n10p57
Accepted: September 2, 2020

Online Published: September 9, 2020

\begin{abstract}
Despite a growing body of research on instructor techniques and treatments to mitigate public speaking anxiety, this issue remains prominent, especially among university students. An alternative to mitigating such anxiety is to identify authentic coping strategies that university students could practice in actual situations. Numerous studies have attempted to explore students' personal and social factors with the objective of suggesting suitable coping strategies to reduce the fear of public speaking. This paper reviews the existing evidence to understand the complexities of strategies that university students use to reduce their fear of public speaking. Nine peer-reviewed studies published between 2015 and 2020 were selected for this review from Science Direct and Google Scholar, using search terms such as "public speaking anxiety" and "coping strategies." The analysis revealed that university students who (a) had an intermediate level of English language proficiency and a high level of speaking anxiety adopted both compensation and metacognitive strategies; (b) had a high level of English language proficiency and speaking anxiety adopted the affective strategy; and (c) had a high level of speaking anxiety and were exposed to full English medium instruction contexts adopted both social and memory strategies. This review, therefore, provides a better understanding of how university students cope with public speaking anxiety and at the same time urges educators to refine their pedagogical methods to lower the psychological barrier of speaking.
\end{abstract}

Keywords: public speaking anxiety, self-coping strategy, university student

\section{Introduction}

From schooling to professional activities, being well-versed in English and able to communicate effectively are prerequisites to increasing one's competence in the professional world (Pandey \& Pandey, 2014). Therefore, the importance of the English language has increased manifold, both at the intranational and international levels. Against this background, being well-versed in English and able to communicate effectively are even more in demand after Malaysia's unemployment rate spiked by 5\% in April, equivalent to more than 60,000 Malaysians and the highest rate of unemployment since 1990 (Jaafar, 2020). Ozturk and Gurbuz (2013) have demonstrated that speaking is the most anxiety-provoking skill. Despite many researchers' efforts to explore authentic coping strategies to mitigate the fear of public speaking among university students, however, most Malaysian graduates still find it difficult to converse in English at job interviews (Mehar Singh \& Chuah, 2012). The reason for such inequity is because there is a limited understanding of different student backgrounds and the instructional environment that they encounter. The objective of this review is to highlight studies of the coping methods that university students use to help reduce their anxiety and thereby help educators refine pedagogical methods to cater to students' needs.

\subsection{Public Speaking Anxiety}

Public speaking anxiety is defined as the fear of speaking in front of audiences. The anxiety extends to preparation of speech (Bodie, 2010). It also often refers to social anxiety disorder, which is known as one of the most common psychological disorders (Ruscio et al., 2008). As Horwitz et al. (1986) asserted, a competent reader or writer is not always a competent speaker. Besides, as Sachdeva (2007) wrote, language learning is not just a matter of understanding but also of speaking in the target language. Nevertheless, people are not born speakers-training is needed (Raja, 2017). 
When students present on stage, they have highlighted themselves in front of the audience and may experience certain signs or symptoms of anxiety. Some of these symptoms include feeling anxiety, nausea, tremors, and excessive sweating in their palms (Kushner, 2004; North \& Rives, 2001). As one participant in Cohen and Norst's (1989) study described:

My heart starts pumping really fast, and the adrenaline runs. Then I feel myself start to go red ... and by the end of the ordeal - for it is - I am totally red, my hands shake and my heart pounds... If anyone laughs at my mistake, I feel really embarrassed and foolish, and the physics of my body don't return to normal for ten minutes or so... It's pure trauma for me. (p. 68)

Moreover, public speaking anxiety can negatively affect education, leading to drop-outs (Schneier et al., 1994); the workforce, leading to low income (Stein et al., 1994); and social relationships, leading to a loss of self-confidence and motivation (Furmark, 2002).

Public speaking anxiety can be experienced as a state-based or trait-like anxiety. State-based anxiety refers to a worsening of anxiety at a point during the speaking. Trait-like anxiety refers to anxiety felt earlier during the preparation stage (Bodie, 2010). Notably, both anxieties can occur concurrently.

\subsection{Coping Strategies-Practicality and Effectiveness}

Although many approaches have tried to manage public speaking anxiety by teaching the most popular techniques of systematic desensitization (McCroskey, 1972), cognitive modification (Allen et al., 1989) and skill training (Whitworth \& Cochran, 1996) to the suffering individuals, the issue of public speaking anxiety remains prevalent. As Bodie (2010) noted, while the level of public-speaking anxiety may decrease, the effectiveness of these approaches is context-specific. The usefulness of these approaches has yet to be validated in the Malaysian context.

Additionally, systematic desensitization, cognitive modification, and skill training rely heavily on teachers to reduce one's level of public speaking anxiety. With the emergence of new teaching pedagogies in the twenty-first century, much more learning is student-oriented, and learner autonomy, therefore, is a primary focus (Raja, 2017). Benson (1997), Murase (2015), and Oxford (2003) agreed to a certain extent that learner autonomy could be determined through different parameters, such as cognitive, social, affective, and behavior. As such, different categorizations have emerged, such as Language Learning Strategies (Oxford, 1990) and the typology of strategies developed by Kondo and Yang (2004). Students, therefore, can regularly self-manage their fear when presenting in front of audiences rather than attending therapies after their situation has worsened.

Yasuda and Nabei (2018), in their discussion of coping strategies for public speaking anxiety, suggested two different points of view: practicality and effectiveness. Practicality indicates that recommended coping strategies should be those that students actually use in their real lives. Because public speaking anxiety could be state-based anxiety, students could adopt and practice particular strategies that are specific to certain settings. It is evident when the degree and sources of anxiety vary greatly between students who use English as a Foreign Language (EFL) and those who use English as a Second Language (ESL). Exemplified by Yasuda and Nabei (2018), EFL students are more afraid of negative judgments from their classmates, while ESL students are more scared of being evaluated negatively by authority figures. These differences are evident when both EFL and ESL students are in an educational setting where the English language is taught as the second language. Students, therefore, need to be clear when adopting particular strategies.

Additionally, another parameter-effectiveness - should be taken into account, as this greatly affects the usage of coping strategies to reduce public speaking anxiety. Yasuda and Nabei (2018) proposed that students should continuously practice the strategies if they are to be effective. However, far too little attention has been paid to authentic coping strategies that students use to alleviate public speaking anxiety (Kondo \& Yang, 2004; Lucas, 1984; Pappamihiel, 2002; Young, 1992). Consequently, little research has been done on the true effects of coping strategies (Yasuda \& Nabei, 2018). This review, therefore, broadens readers' understanding of the complexities of university students' strategies in mitigating their public speaking anxiety.

\section{Method}

A systematic search was performed in compliance with the guidelines for qualitative and quantitative analysis of Preferred Reporting Products for Systematic Reviews and Meta-Analyses (PRISMA; Moher et al., 2010).

\subsection{Data Sources}

The research papers were sourced from Google Scholar and Science Direct electronic databases, respectively. The papers were published between January 2015 and July 2020. Search terms with specified filters were 
developed using nested clauses and multiple Boolean operators, AND and OR. These included: ("public speaking anxiety" OR "speaking anxiety") AND coping strategies; ("speaking anxiety" OR "communication apprehension") AND strategies; ("public speaking anxiety" OR "communication apprehension") AND self-regulatory strategies; fear of public speaking ("coping strategies" OR "strategies"); strategies ("fear of public speaking" OR "communication apprehension"). Meanwhile, the "Related articles" link under the search results in Google Scholar was also used to find potentially relevant papers.

\subsection{Inclusion Criteria}

Research papers were identified using the following requirements: (a) published between 2015 and 2020; (b) published in the English or Malay language; (c) focused on undergraduates; (d) had full text available; and (e) included primary findings about students' strategies to cope with speaking anxiety, communication apprehension, and/or the fear of public speaking.

\subsection{Study Selection and Data Extraction}

Endnote software was used to import all relevant research papers and delete duplicate papers. The first screening process was then conducted; papers were removed if their abstracts did not meet the inclusion criteria. Remaining papers were selected and critically reviewed in the second screening process based on the following exclusion criteria: (a) review paper; (b) full text is not available; (c) no focus on undergraduates; and (d) coping/self-regulatory strategies are stated as implications for the studies. Data was then extracted into a predefined table with the following headings: (a) researcher(s) and year of publication; (b) location of research; (c) research objectives; (d) descriptions of the research participants, including course year, course program, and/or the English level; (e) research approach; (f) method(s) of data collection; (g) reliability and validity; (h) research findings; and (i) limitations. Table 1 shows a summary of studies with the exclusion criteria.

Table 1. Summary of Studies with the Exclusion Criteria

\begin{tabular}{|c|c|c|c|c|c|c|c|}
\hline $\begin{array}{l}\text { Researcher(s), } \\
\text { Year of publication, } \\
\text { Location of research }\end{array}$ & $\begin{array}{l}\text { Research } \\
\text { objectives }\end{array}$ & Subjects & $\begin{array}{l}\text { Research } \\
\text { design/ } \\
\text { Research } \\
\text { approach }\end{array}$ & $\begin{array}{l}\text { Method(s) of } \\
\text { data collection }\end{array}$ & $\begin{array}{l}\text { Reliability } \\
\text { (Cronbach's } \\
\text { alpha)/Validity } \\
\text { (Exploratory and } \\
\text { Confirmatory } \\
\text { Factor Analysis) }\end{array}$ & Major findings & Limitations \\
\hline
\end{tabular}

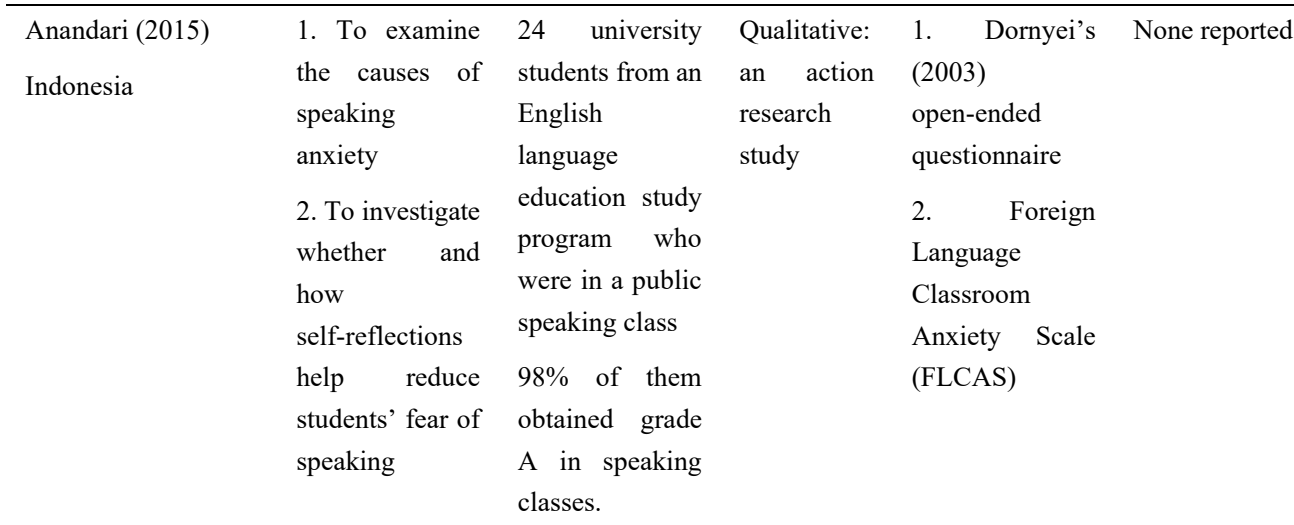

El-Sakka (2016)

Egypt

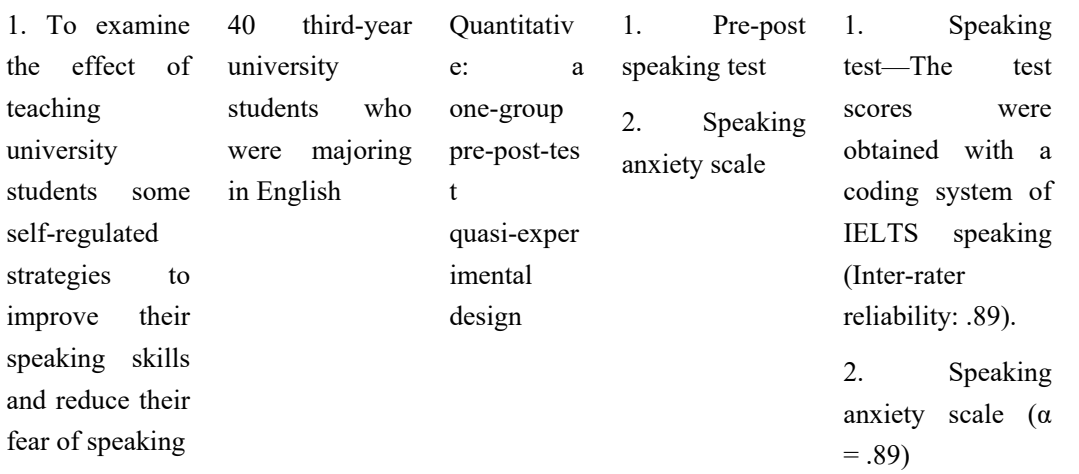

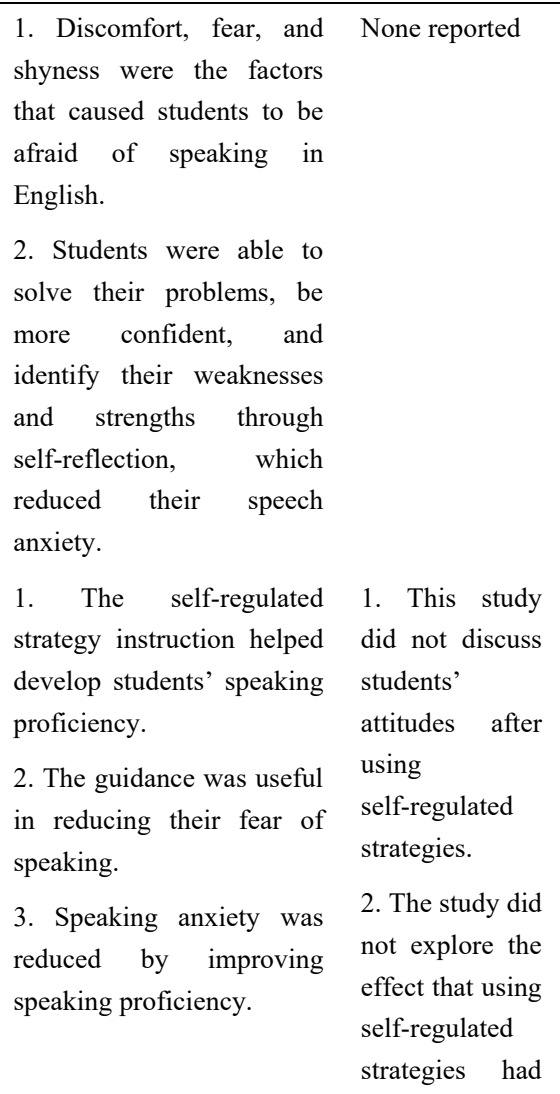


Genc, Kulusakli, \& 1. Aydin (2016)

Turkey

He (2017)

China investigate the relationship

between

speaking anxiety levels and strategy use

(1)$$
\text { hours of English }
$$$$
\text { instruction }
$$

weekly

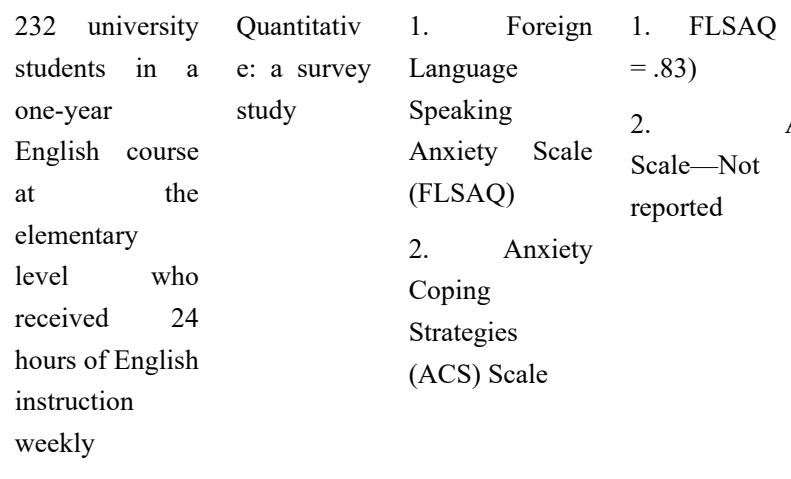

1. To explore strategies for alleviating students' speaking anxiety

2. To examine the

effectiveness of the strategies explored
302 university Quantitativ 1. Survey with 1. Questionnaire I students from engineering,

e: experiment questionnaires business, arts, al study and science majors and 30 English lecturers from two universities in China $(\alpha=.86)$

2. Questionnaire $2 . \quad$ Focus
interview

II $(\alpha=.88)$
3. Interviews were conducted Chinese.

4. Questionnaire
data were
cross-validated
with interview
data.

on communication skills.

1. The researchers only studied a small group of university students in a state university.

2. The data analysis was overly simplified; no complicated analytical techniques or comprehensive analysis were utilized.

1. A correlation between speaking anxiety level and oral proficiency level was not found.

2. The researcher was unable to monitor the application of strategies in the testing phase or the

effectiveness of the explored strategies

because the two universities were far apart.

3. The researcher tried to maintain usual English teaching, and some unforeseen external factors may have influenced the findings. 


$\begin{array}{llrl}\begin{array}{l}\text { Rafada \& Madini } \\ \text { (2017) }\end{array} & \begin{array}{l}1 . \\ \text { investigate EFL }\end{array} & \begin{array}{l}\text { Random } \\ \text { sampling }\end{array} \\ \text { Saudi Arabia } & \begin{array}{l}\text { students' } \\ \text { perceptions }\end{array} & 10 \text { female } \\ & \text { about speaking } \\ & \text { anxiety } & \begin{array}{l}\text { students, from } \\ \text { elementary, }\end{array} \\ & 2 . \text { To devise } & \text { pre-intermediate } \\ & \text { strategies that } & \text { and } \\ & \text { help reduce } & \text { intermediate } \\ & \text { students' } & \text { levels aged } \\ & \text { speaking } & \text { between 18 and } \\ & \text { anxiety } & 20 \text { years old }\end{array}$

Chou (2018)

Taiwan

Pratama,

Ikhsanudin,

Salam (2018)

Indonesia

1. To address the differences in the use of speaking

strategies

attributable to the

English-Mediu

$\mathrm{m}$ Instruction

(EMI) type

2.

investigate

whether using

strategies can

help predict the

fear of speaking
638 second-year university students from four universities who had achieved either A2 or B1 level in the Common European Framework of Reference for Languages (CEFR)
Qualitative 1.

Semi-structured interview

conducted in

1. Negative thoughts about

Arabic

\begin{tabular}{|c|c|c|}
\hline \multirow{5}{*}{$\begin{array}{l}\text { Quantitativ } \\
\text { e: a survey } \\
\text { study }\end{array}$} & 1. FLCAS & \multirow{2}{*}{$\begin{array}{l}\text { 1. FLCAS }(\alpha \\
=.92)\end{array}$} \\
\hline & 2. Language & \\
\hline & \multirow{2}{*}{$\begin{array}{l}\text { Survey—Speaki } \\
\text { ng Strategy Use }\end{array}$} & \multirow{3}{*}{$\begin{array}{l}2 . \quad \text { Language } \\
\text { Strategy Use } \\
\text { Survey-Speakin } \\
\text { g Strategy Use ( } \alpha \\
=.87)\end{array}$} \\
\hline & & \\
\hline & $\begin{array}{l}3 . \quad \text { An } \\
\text { open-ended }\end{array}$ & \\
\hline
\end{tabular}

1. To examine \& causes of the fear of speaking in a public speaking class

2. $\begin{array}{lr}2 . & \text { To } \\ \text { investigate } & \text { a }\end{array}$ student's strategies in reducing the fear
A 3rd-semester student in the Speaking for Academic Presentation class who had developed strategies to overcome the fear of speaking and had successfully

\section{English speaking tests}

five-component

FLCAS solution explained a total variance $57.68 \%$.

4. three-component Speaking Strategy Use solution explained a total variance of $61.65 \%$.

5. Analytic descriptors of spoken language were adapted from the CEFR to evaluate students' speaking.

Qualitative: 1. Personal None reported narrative inquiry

2.

Semi-structured interview

3. Direct observation
1. Lack of preparation, lack of self-confidence, fear of being the focus, and afraid of making mistakes were the factors contributing to public speaking anxiety.

2. Strategies such as visualization, relaxation, gestures, using cue cards, and rehearsal were effective in reducing fear.
1. The research findings are not generalizable

because only subjects with low- to mid-level

English proficiency were included.

2. Due to social rules, the study only focused on females.

1. This study only focused on two aspects: speaking anxiety and strategies to reduce the fear. 2. Feedback/opini ons from teachers and students failed to support the findings further.
1. This study was context-specific and thus cannot be generalizable to a larger population.

2. There was no investigation of the sources of students' 
overcome the

fear

$\begin{array}{ll}\text { Widhayanti (2018) } & \text { 1. To explore } \\ \text { Indonesia } & \text { the factors that } \\ \text { provoke } & \text { students' } \\ & \text { speaking } \\ \text { anxiety } & \\ & \text { 2. To identify } \\ & \text { learning } \\ & \text { strategies that } \\ & \text { students use to } \\ & \text { overcome } \\ & \text { speaking } \\ \text { anxiety }\end{array}$

$\begin{array}{lll}\text { Yasuda \& Nabei } & \begin{array}{l}\text { 1. To examine } \\ \text { the effects of }\end{array} & \begin{array}{l}\text { One third-year, } \\ \text { the second-year, }\end{array} \\ \text { Japan } & \text { five coping } & \text { and } 72 \text { first-year } \\ & \text { strategies } & \text { undergraduates } \\ & \text { (relaxation, peer } & \text { in a compulsory } \\ & \text { seeking, } & \text { English class in } \\ \text { positive } & \text { the Department } \\ & \text { thinking, } & \text { of Science, who } \\ & \text { preparation, and } & \text { had achieved at } \\ & \text { resignation) in } & \text { least A2 level in } \\ & \text { reducing } & \text { the CEFR } \\ & \text { classroom } & \\ & \text { speaking } & \\ & \text { anxiety } & \end{array}$

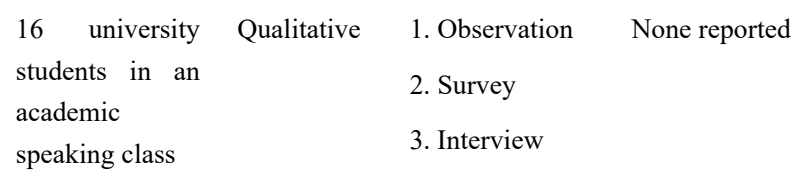

\begin{tabular}{|c|c|c|}
\hline Quantitativ & 1. Coping & 1. Coping strategy \\
\hline e: & strategy & language \\
\hline correlationa & language & anxiety $(\alpha=.72)$ \\
\hline 1 study & anxiety adopted & 2. FLCAS $(\alpha$ \\
\hline & from Kondo \& & $=.82)$ \\
\hline & Yang (2004) & Weaver's \\
\hline & 2. FLCAS & (2010) L2 WTC \\
\hline & 3. Weaver's & Questionnaire $\quad(\alpha$ \\
\hline & (2010) & $=.94)$ \\
\hline & Willingness to & \\
\hline & Communicate & \\
\hline & (WTC) & \\
\hline & Questionnaire & \\
\hline
\end{tabular}

anxiety or how different types of anxious students curb their fear in different situations.

1. The study does not explain why the mentioned circumstances lead to speaking anxiety.

2. The study also does not explain how these strategies help students minimize their fear of speaking.

1. Coping strategies correlated positively with WTC.

1. The effects of these five coping strategies were not significant, possibly due to the limited time frame of the study.

2. This study did not take personality factors into account.

\subsection{Search Results}

The search strategies identified a total of 358 unique results. Of these papers, 39 duplicates were returned, leaving 319 hits for further screening. The reviewer evaluated the articles from abstracts, and a total of 21 runs were provisionally chosen for full-text review. Considering the exclusion criteria, nine papers were selected for this review, as illustrated in the PRISMA flowchart (see Figure 1). 


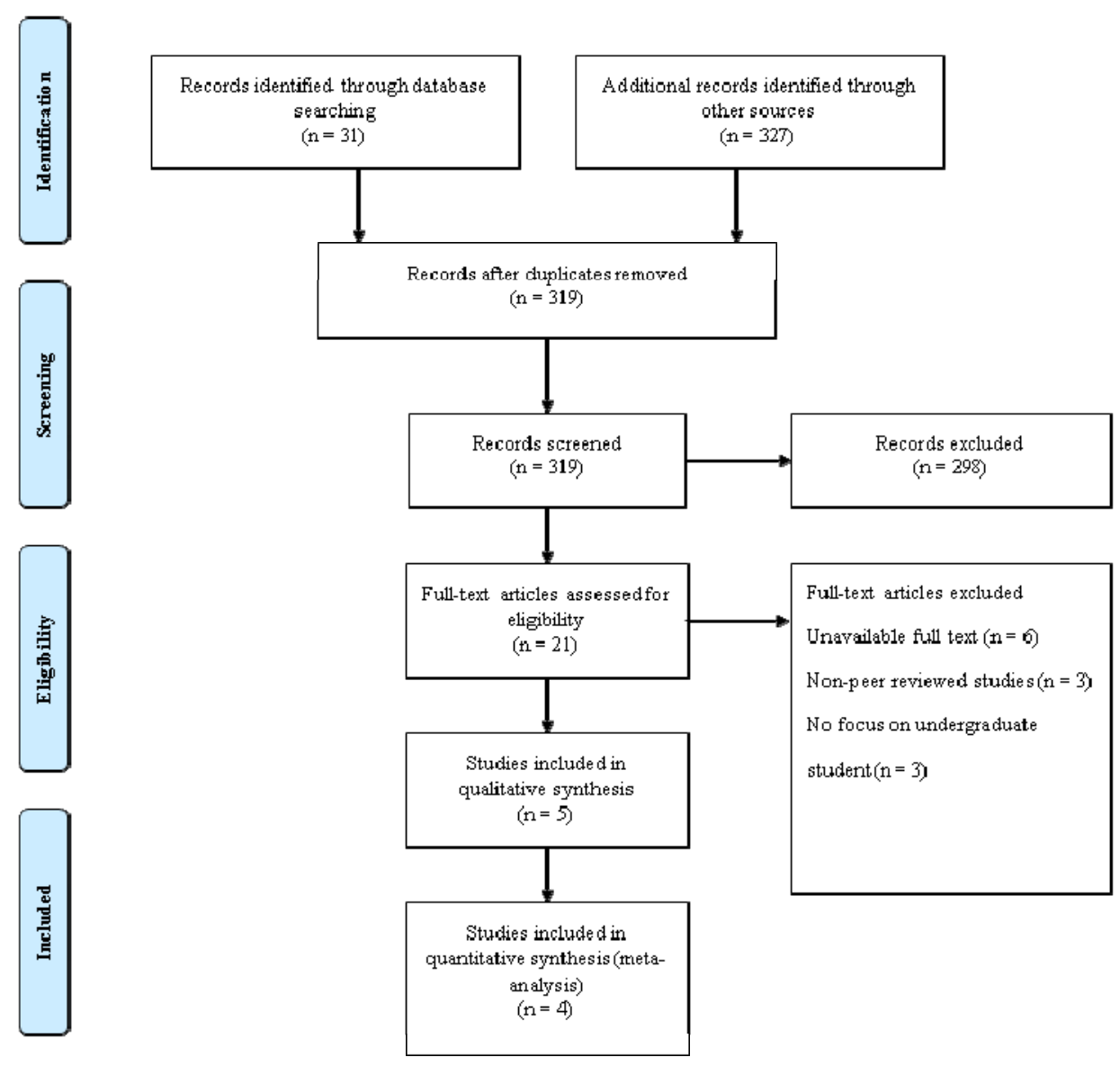

Figure 1. The PRISMA Flowchart

\subsection{Quality Appraisal}

In terms of methodologies, it was found that four studies were qualitative, two used a quasi-experimental design, another two were survey studies, and one was a correlational study. A semi-structured interview was the most popular instrument used for qualitative studies, whereas validated questionnaires were adopted in all quantitative studies. The Foreign Language Speaking Anxiety Scale (FLSAQ), the Anxiety Coping Strategies (ACS) Scale, and the Foreign Language Classroom Anxiety Scale (FLCAS) were the most popular instruments used to measure public speaking anxiety levels and the strategies used to cope with the fear.

To determine their methodological rigor, qualitative studies were assessed based on the trustworthiness of results, while quantitative studies were assessed based on the validity and reliability of results. After identifying the research approach of each of these nine papers, the risk of bias in the four qualitative papers was assessed using the Critical Appraisal Skills Programme (CASP). Meanwhile, questions from the Joanna Briggs Institute (JBI) Critical Appraisal tool were adopted to assess the quality of quasi-experimental studies, and the checklists developed by Roever (2015) were used to critically analyze survey studies. Also, the National Institute for Health and Care Excellence (NICE) Checklist was used for a quantitative research reporting correlation. An overall summary of these assessments is presented using a range of grading systems in Tables 3, 4, 5, and 6 . After obtaining the sum score of each assessment, the included papers were determined to be of varying quality, with the survey studies (Chou, 2018; Genc et al., 2016) being of the lowest quality. The qualitative studies (Anandari, 2015; Pratama et al., 2018; Rafada \& Madini, 2017; Widhayanti, 2018) and experimental studies (El-Sakka, 2016; He, 2017) were deemed high quality. The remaining papers were rated as medium quality. 
Table 3. Quality Appraisal of Included Qualitative Studies

\begin{tabular}{|c|c|c|c|c|c|c|c|c|}
\hline Researcher(s) and year of publication & (Ane & ndari, 2015) & & $\begin{array}{l}\text { lafada \& } \\
\text { lini, 2017) }\end{array}$ & & $\begin{array}{l}\text { tama et al., } \\
\text { 2018) }\end{array}$ & & $\begin{array}{l}\text { idhayanti, } \\
\text { 2018) }\end{array}$ \\
\hline CASP question & Yes & $\begin{array}{l}\text { Can't No } \\
\text { tell }\end{array}$ & Yes & $\begin{array}{l}\text { Can't No } \\
\text { tell }\end{array}$ & Yes & $\begin{array}{ll}\text { Can't } & \text { No } \\
\text { tell }\end{array}$ & Yes & $\begin{array}{ll}\text { Can't } & \text { No } \\
\text { tell }\end{array}$ \\
\hline $\begin{array}{l}\text { Was there a clear statement of the aims of } \\
\text { the research? }\end{array}$ & - & & $\bullet$ & & - & & • & \\
\hline Is a qualitative methodology appropriate? & $\bullet$ & & $\bullet$ & & $\bullet$ & & $\bullet$ & \\
\hline $\begin{array}{l}\text { Was the research design appropriate to } \\
\text { address the aims of the research? }\end{array}$ & $\bullet$ & & • & & $\bullet$ & & $\bullet$ & \\
\hline $\begin{array}{l}\text { Was the recruitment strategy appropriate } \\
\text { to the aims of the research? }\end{array}$ & • & & & $\bullet$ & $\bullet$ & & & • \\
\hline $\begin{array}{l}\text { Was the data collected in a way that } \\
\text { addressed the research issue? }\end{array}$ & $\bullet$ & & $\bullet$ & & • & & - & \\
\hline $\begin{array}{l}\text { Has the relationship between researcher } \\
\text { and participants been adequately } \\
\text { considered? }\end{array}$ & • & & • & & $\bullet$ & & $\bullet$ & \\
\hline $\begin{array}{l}\text { Have ethical issues been taken into } \\
\text { consideration? }\end{array}$ & & $\bullet$ & $\bullet$ & & & • & & $\bullet$ \\
\hline $\begin{array}{l}\text { Was the data analysis sufficiently } \\
\text { rigorous? }\end{array}$ & • & & & $\bullet$ & $\bullet$ & & • & \\
\hline Is there a clear statement of findings? & $\bullet$ & & $\bullet$ & & $\bullet$ & & $\bullet$ & \\
\hline Is the research valuable? & & • & $\bullet$ & & • & & $\bullet$ & \\
\hline Grading & $8 / 10$ & & $8 / 10$ & & $9 / 10$ & & $8 / 10$ & \\
\hline
\end{tabular}

Table 4. Quality Appraisal of Included Experimental Studies

\begin{tabular}{|c|c|c|c|c|c|c|c|c|}
\hline \multirow{2}{*}{$\begin{array}{l}\text { Researcher(s) and year of publication } \\
\text { Appraisal question }\end{array}$} & \multicolumn{4}{|c|}{ (El-Sakka, 2016) } & \multicolumn{4}{|c|}{$(\mathrm{He}, 2017)$} \\
\hline & Yes & No & Unclear & $\begin{array}{l}\text { Not } \\
\text { applicable }\end{array}$ & Yes & No & Unclear & $\begin{array}{l}\text { Not } \\
\text { applicable }\end{array}$ \\
\hline $\begin{array}{l}\text { Is it clear in the study what is the "cause" and what is the } \\
\text { "effect" (i.e., there is no confusion about which variable } \\
\text { comes first)? }\end{array}$ & • & & & & • & & & \\
\hline Were the participants included in any comparisons similar? & $\bullet$ & & & & $\bullet$ & & & \\
\hline $\begin{array}{l}\text { Were the participants included in any comparisons } \\
\text { receiving similar treatment/care, other than the exposure or } \\
\text { intervention of interest? }\end{array}$ & $\bullet$ & & & & $\bullet$ & & & \\
\hline Was there a control group? & & • & & & • & & & \\
\hline $\begin{array}{l}\text { Were there multiple measurements of the outcome both } \\
\text { before and after the intervention/exposure? }\end{array}$ & $\bullet$ & & & & $\bullet$ & & & \\
\hline $\begin{array}{l}\text { Was follow-up complete and if not, were differences } \\
\text { between groups in terms of their follow-up adequately } \\
\text { described and analyzed? }\end{array}$ & ○ & & & & • & & & \\
\hline $\begin{array}{l}\text { Were the outcomes of participants included in any } \\
\text { comparisons measured in the same way? }\end{array}$ & $\bullet$ & & & & $\bullet$ & & & \\
\hline Were outcomes measured in a reliable way? & $\bullet$ & & & & • & & & \\
\hline Was appropriate statistical analysis used? & • & & & & • & & & \\
\hline Overall appraisal & $9 / 10$ & & & & $10 / 10$ & & & \\
\hline
\end{tabular}


Table 5. Quality Appraisal of Included Survey Studies

\begin{tabular}{|c|c|c|}
\hline Researcher(s) and year of publication & (Genc, Kulusakli, \& Aydin, 2016) & (Chou, 2018) \\
\hline \multicolumn{3}{|l|}{ Appraisal question } \\
\hline Q1 & Yes & Yes \\
\hline Q2 & Yes & Yes \\
\hline Q3 & Yes & Yes \\
\hline Q4 & Yes & No \\
\hline Q5 & Yes & Yes \\
\hline Q6 & Yes & The pilot test is not mentioned \\
\hline Q7 & Yes & Yes \\
\hline Q8 & Can’t tell & Yes \\
\hline Q9 & Yes & Yes \\
\hline Q10 & Can't tell & Can't tell \\
\hline Q11 & Yes & Yes \\
\hline Q12 & Can't tell & Yes \\
\hline Q13 & Not reported & Not reported \\
\hline Q14 & Not reported & Not reported \\
\hline Q15 & Not reported & Not reported \\
\hline Q16 & Not reported & Not applicable \\
\hline Q17 & Not reported & Not applicable \\
\hline Q18 & Not applicable & Not applicable \\
\hline Q19 & Yes & Yes \\
\hline Q20 & Yes & Yes \\
\hline Q21 & Not reported & Not reported \\
\hline Q22 & Not reported & Through interlocutors \\
\hline Q23 & No & No \\
\hline Q24 & No & No \\
\hline Q25 & Yes & Yes \\
\hline Q26 & Yes & Yes \\
\hline Q27 & No & No \\
\hline Q28 & Yes & Yes \\
\hline Q29 & Yes & Yes \\
\hline Q30 & Not applicable & Yes \\
\hline Q31 & Yes & Yes \\
\hline Q32 & Yes & Yes \\
\hline Q33 & $\begin{array}{l}\text { All relevant results have been reported. } \\
\text { There is no evidence of "data } \\
\text { dredging." }\end{array}$ & $\begin{array}{l}\text { All relevant results have been } \\
\text { reported. There is no evidence of } \\
\text { "data dredging." }\end{array}$ \\
\hline Q34 & Yes & Yes \\
\hline Q35 & Yes & Yes \\
\hline Q36 & Yes & Yes \\
\hline Q37 & No & No \\
\hline Grading & $\begin{array}{l}\text { Acceptable }(+) \text { : Most criteria met. } \\
\text { Some flaws in the study with an } \\
\text { associated risk of bias. }\end{array}$ & $\begin{array}{l}\text { Acceptable }(+) \text { : Most criteria met. } \\
\text { Some flaws in the study with an } \\
\text { associated risk of bias. }\end{array}$ \\
\hline
\end{tabular}


Table 6. Quality Appraisal of Included Correlational Study

\begin{tabular}{ll}
\hline Researcher(s) and year of publication & (Chou, 2018) \\
\hline Appraisal question & ++ \\
\hline Is the source population or source area well described? & \\
Is the eligible population or area representative of the source & ++ \\
population or area? & \\
Do the selected participants or areas represent the eligible population \\
or area?
\end{tabular}

How was selection bias minimized in the selection of the exposure (and comparison) group?

ESAP courses were offered in the full and partial EMI contexts regardless of students' English proficiency level. This minimizes a potential bias toward the self-selection of EMI programs by the students.

Was the selection of explanatory variables based on a sound + theoretical basis?

Was the contamination acceptably low?

$++$

How well were likely confounding factors identified and controlled? ++

Is the setting applicable to the UK?

Not applicable

Were the outcome measures and procedures reliable?

$++$

$++$

Were the outcome measurements complete?

$++$

Were all the important outcomes assessed?

Was there a similar follow-up time in exposure and comparison groups?

Was follow-up time meaningful?

Was the study sufficiently powered to detect an intervention effect (if one exists)?

Were multiple explanatory variables considered in the analyses?

Were the analytical methods appropriate?

Was the precision of association given or calculable? Is the association meaningful?

Are the study results internally valid (i.e., unbiased)?

Are the findings generalizable to the source population (i.e., externally valid)?

Grading

+ Some of the checklist criteria have been fulfilled; where they have not been fulfilled, or not adequately described, the conclusions are unlikely to alter.

\subsection{Strengths and Weaknesses}

Through the process of quality appraisal, the researchers identified that, across the nine papers, (i) studies rarely reported whether a pilot test was undertaken before adopting or using the instruments in their actual research; (ii) studies included inadequate information about sampling methods and frameworks, which suggested that the transferability and generalizability of the research outcomes to the same population or context was limited; and (iii) no studies discussed sample size. Across the selected papers, suitable power calculation was not included in the studies. Nonetheless, most of the included studies used a prospective design, adopted valid and reliable instruments for measuring public speaking anxiety and detecting coping strategies used by undergraduates, discussed the findings based on the theories or concepts, and reviewed relevant literature. 
While these nine papers provide insights about university students' public speaking anxiety levels, their choices of coping strategies, and the effectiveness of particular strategies, caution should be taken when drawing conclusions from the findings. For instance, four papers (Anandari, 2015; Rafada \& Madini, 2017; Pratama et al., 2018; Widhayanti, 2018) only solicited students' opinions and reported the findings, which might have resulted in a response bias. Meanwhile, the effectiveness of some of the strategies mentioned by respondents was statistically proved in experimental studies (El-Sakka, 2016; He, 2017), which ultimately restricts the establishment of potential relationships between speaking anxiety levels and strategy use. Only one survey study (Genc et al., 2016) reported the preference of strategy used by participants with high, medium, and low levels of speaking anxiety without considering personality factors.

\section{Results}

The nine papers included in this review were from Taiwan $(n=1)$, Indonesia $(n=3)$, Egypt $(n=1)$, Japan $(n=$ 1), China ( $(n=1)$, Saudi Arabia $(n=1)$, and Turkey $(n=1)$. The findings are reported based on the responses and narratives elicited from 1,421 university students. Most of the university students in the included studies were in a foundational program or in the second year of their degree of study. Forty students were third-year undergraduates. While five studies (El-Sakka, 2016; Genc et al., 2016; He, 2017; Pratama et al., 2018; Widhayanti, 2018) did not report students' English proficiency levels, other studies included participants who were either a mixture of English proficiency levels (Rafada \& Madini, 2017) or at least B1 achievers in the Common European Framework of Reference for Languages (Anandari, 2015; Chou, 2018; Yasuda \& Nabei, 2018).

While six studies used the reviewed literature to guide their data collection and analysis, El-Sakka's research (2016) was backboned by Bandura's social cognitive theory. The study conducted and carried out by Rafada and Madini (2017) used Krashen's Affective Filter Hypothesis to describe how affective filters hinder the act of speaking and learning. Yasuda and Nabei (2018) also used the concept of willingness to communicate to explain the fear of speaking.

Considering the research objectives and findings, five subthemes were identified: (a) types of strategies used to cope with speaking anxiety; (b) language proficiency level and strategies used to reduce speaking anxiety; (c) full English medium-instruction context and strategies used to cope with speaking anxiety; (d) high level of speaking anxiety and strategies used to reduce speaking anxiety; and (e) effectiveness of the strategies used for speaking anxiety. These five subthemes mainly reflect three broader themes. The first theme encompasses common types of speaking strategies despite different categorizations found in the included studies.

\subsection{Types of Strategies Used to Cope with Speaking Anxiety}

Findings show that the typology of strategies by Kondo and Yang (2004) and language learning strategies (LLS) by Oxford (1990) were commonly used to report students' strategies for coping with speaking anxiety. Meanwhile, other studies combined strategies as a single unit. In this review, LLS is the tool used to report and group the strategies used to reduce the fear of speaking because (1) it can merge five strategies stated by Kondo and Yang (2004); (2) LLS is more comprehensive than Kondo and Yang's typology; and (3) the types of strategies detailed in LLS fit the context of speaking. The six strategies outlined in LLS are memory, cognitive, compensation, metacognitive, affective, and social strategies.

\subsubsection{Memory Strategy}

The concept of memory strategy is about storing and retrieving new information in one's memory. Techniques such as imagery, reviewing further information, and creating mental strategies to reduce the fear of speaking fall under this strategy type (Oxford, 1990). Two studies found that students who applied memory strategy to mitigate speaking anxiety were likely to review their note cards before going on stage or waiting for their presentation (Widhayanti, 2018). Interestingly, some of them would reread the scripts or short notes to remember the points when they did not bring any palm notes on stage (Widhayanti, 2018). While others blindly memorized the points, some tried to understand the presentation topic to ease memorization. Indeed, students also imitated native speakers' speech (Chou, 2018) when presenting by memorizing the intonation and body language of native speakers' speaking.

\subsubsection{Cognitive Strategy}

A slight difference between memory strategy and cognitive strategy is that the latter involves direct transformation or manipulation. Techniques used to reduce the fear of speaking include practicing, reasoning, and analyzing, as well as making a structure for input and output (Oxford, 1990). The review found that students who used cognitive strategy to overcome speaking anxiety rehearsed (Pratama et al., 2018) and recorded their 
presentation in front of a mirror before the day of the performance as well as practiced silently while waiting their turn to present (Widhayanti, 2018).

\subsubsection{Compensation Strategy}

This strategy is used when students compensate for lack of vocabulary in speaking and try to guess the content or output intelligently to aid comprehension or speech production and overcome the fear of speaking (Oxford, 1990). The review showed that students would select familiar topics if they were allowed to do so to reduce their nervousness on stage. When they could not retrieve certain words in the target language when presenting on stage, they used gestures or mime (Pratama et al., 2018; Widhayanti, 2018), synonyms, simple vocabularies (He, 2017), direct translation, and code-switching (Chou, 2018). Before speaking, some students also mastered the topic of the presentation to keep calm on stage. Contrary to expectations, some of them put effort into selecting their presentation outfit to create a strong visual impact, as well as ensure their clothes communicated first before their speech (Widhayanti, 2018); read English books; and watched English movies (He, 2017; Rafada \& Madini, 2017).

\subsubsection{Metacognitive Strategy}

This strategy often requires students to plan, monitor, evaluate, and make changes in their speaking. Taking these actions leads students to monitor their speaking and identify when something has to be changed because it is unsuitable (Oxford, 1990). Some included studies reported that students drafted their script (Pratama et al., 2018; Widhayanti, 2018) and organized their speech before the presentation to reduce the fear of speaking. Some said they watched related YouTube videos or television shows (He, 2017), focused on English pronunciation (Rafada \& Madini, 2017), and prepared props a few days before the presentation to synchronize their props with their speech notes. Other students reported that they synced their speech with other members if it was a group presentation to reduce the uncertainty that would arouse the fear. Furthermore, some recorded their rehearsals and replayed the recordings to review their performance (Widhayanti, 2018).

\subsubsection{Affective Strategy}

Oxford (1990) mentioned that affective filters are essential in language learning because they control learners' emotions, feelings, motivations, and even values toward language learning. The same is applied to coping with speaking anxiety. Widhayanti (2018) found that students would listen to music, take a deep breath, meditate, and perform the dhikr - an Islamic devotional act. While waiting to be on stage, some students walked around the classroom, had positive thoughts about the upcoming performance (Genc et al., 2016) or self-talked (He, 2018), and shared feelings with their friends to reduce the fear (He, 2017; Widhayanti, 2018). Writing self-reflections before and after the presentation to record their emotions at those times (Anandari, 2015) and playing games (He, 2017) were also ways to alleviate their fear of speaking. However, some students who experienced speaking anxiety gave up on putting in the effort to improve their performance and avoided talking on stage if it was allowed (Genc et al., 2016).

\subsubsection{Social Strategy}

Social strategy is another strategy used by students because presenting in front of others seeks mutual comprehension between the presenter and audiences. To achieve that mutual understanding, students would find social support-for example, asking their peers to check on them after rehearsing their speech. Some would also ask for help from their friends if their minds went blank during a group presentation (Widhayanti, 2018). Some students even joined a summer English program (Rafada \& Madini, 2017) to have more opportunities to practice speaking English with other students from different classes.

\subsection{Learner Characteristics and Strategies Used to Cope with Speaking Anxiety}

Understanding different strategies for coping with speaking anxiety also necessitated reviewing learner characteristics as a potential factor in selecting suitable strategies. The three sections below highlight how students' language proficiency level, full English medium-instruction context, and high level of speaking anxiety relate to their use of different types of strategies.

\subsubsection{Language Proficiency Level and Strategies Used to Reduce Speaking Anxiety}

Although there was no clear relationship between language proficiency level and strategy use on speaking anxiety, four studies revealed that university students with different language proficiency levels used different coping strategies to reduce the fear of speaking. It was reported that Indonesian students who achieved an A grade in public speaking classes showed a significant reduction in speaking anxiety when they wrote self-reflections to express their emotions before and after the presentation (Anandari, 2015). On the other hand, 
Taiwanese students who achieved either level A2 or B1 in the Common European Framework of Reference for Languages used borrowing, paraphrasing, and rehearsal strategies to cope with the fear of speaking regardless of English medium instruction contexts (Chou, 2018). Meanwhile, relaxation and peer seeking strategies did not work on university students who achieved scores of 300 to 400 in the Test of English for International Communication (TOEIC) - an equivalent of level A2 in the CEFR (Yasuda \& Nabei, 2018). Indeed, preparation and positive thinking helped the students alleviate the anxiety of speaking when it was an influential factor in their willingness to communicate. In contrast to Yasuda and Nabei (2018), resignation was recorded as the most commonly used strategy and positive thinking as the least used among primary language level university students (Genc et al., 2016).

Overall, with these insightful datasets, the studies illustrated that compensation and metacognitive strategies - categorized according to Oxford's LLS (1990) - were of great use among students with intermediate or elementary language level. Two of the datasets also showed that affective strategy was popular among Level A1 and grade A achievers while social strategy was not as popular among primary language level university students.

\subsubsection{Full English Medium-Instruction Context and Strategies Used to Cope with Speaking Anxiety}

The English medium-instruction context has raised curiosity about how much university students were exposed to the target language in classes. Across all studies, participants in English-speaking courses and classes in the semester in which the studies were carried out were selected. However, eight papers did not mention the types of English medium instruction contexts used in classes-in other words, whether lecturers code-switched (partial) or entirely used (full) the target language to deliver the lessons remains unknown, and presuppositions should not be taken. Only one of the included studies (Chou, 2018) had access to the types of strategies used, individually, in settings of partial and full English medium instruction. It was revealed that rehearsal techniques, such as starting conversations as frequently as possible, imitating how native speakers speak English, or creating opportunities to converse with native speakers, were used by university students in a full English medium-instruction context to reduce their fear of speaking. Also, they used synonyms —one of the paraphrasing strategies - to better express themselves through conversation than those who were in partial English medium-instruction contexts. Interestingly, it was found that students who frequently used borrowing techniques, such as gesturing, code-switching, and direct translating, albeit in partial or full English medium-instruction contexts, reported a higher level of speaking anxiety.

In sum, borrowing and paraphrasing techniques, categorized as compensation strategies based on Oxford's LLS (1990), indirectly indicated that compensation strategies have some adverse effects on university students' speaking anxiety levels. On the other hand, the effectiveness of rehearsal techniques that combined memory and social strategies demonstrated that memory and social strategies are the most practical coping strategies for university students who had a fear of speaking in a full English medium-instruction context.

\subsubsection{High Level of Speaking Anxiety and Strategies Used to Reduce Speaking Anxiety}

University students with different anxiety levels use different types of strategies to reduce their fear of speaking. Four papers (Anandari, 2015; Chou, 2018; Genc et al., 2016; He, 2017) reported that participants in their studies experienced a high level of speaking anxiety. Findings showed that university students with high speaking anxiety levels relied on compensation (Chou, 2018; He, 2017), memory (Chou, 2018), social (Chou, 2018; He, 2017), affective (Anandari, 2015; Chou, 2018; Genc et al., 2016; He, 2017), and metacognitive strategies (Chou, 2018; He, 2017) to mitigate their fear. For instance, teacher participants in He's study (2017) gave sample presentations for students to imitate and perform the speaking. However, there is a discrepancy between He's (2017) findings and Chou's (2018): students who frequently imitated a native speaker's way of speaking did not reduce their fear of speaking but rather developed a higher degree of speaking anxiety. As for the affective strategy, some university students gave up the situation and avoided presenting if they could (Genc et al., 2016). Some techniques under this strategy were nonetheless useful. For example, writing self-reflections by noting their genuine emotions before and after the speaking reduced students' fear (Anandari, 2015), allowing them to imagine themselves performing well on stage ( $\mathrm{He}, 2017)$ and helping them to relax $(\mathrm{He}, 2017)$.

\subsection{Effectiveness of the Strategies Used for Speaking Anxiety}

Among all the papers discussed, only four papers (Anandari, 2015; El-Sakka, 2016; He, 2017; Yasuda \& Nabei, 2018) reported the effectiveness of the strategy used. A strategy was considered valid when (1) the students were willing to communicate (Yasuda \& Nabei, 2018); (2) the paired samples' t-test showed that there was a significant difference between mean scores of the pre- and post-tests of speaking anxiety (El-Sakka, 2016; He, 2017); and (3) it was proved through students' narratives (Anandari, 2015). A reduced speaking anxiety level 
was vividly shown when students who employed preparation and positive thinking techniques were more willing to communicate. Additionally, preparation, repetition, help-seeking, elaboration, rehearsal, and organizational techniques were practical when students showed improvements in their post-speaking test. Against expectations, peer seeking was deemed ineffective when it showed no effect on speaking anxiety. However, two of these papers came to contradictory statements about this strategy's effectiveness (He, 2017; Yasuda \& Nabei, 2018). Using the stepwise regression method, He (2017) reported that relaxation techniques had no effect on speaking anxiety; however, Yasuda and Nabei (2018) found that students scored better on the post-speaking test after applying the technique. Such a difference may be attributed to students' personalities. Furthermore, writing self-reflections proved useful when students were able to see their weaknesses and strengths, overcome their weaknesses, and boost self-confidence (Anandari, 2015).

In sum, the studies revealed some techniques that university students practiced to reduce speaking anxiety. Only three studies (Anandari, 2015; El-Sakka, 2016; He, 2017) attempted to conduct longitudinal research to observe the participants for 3-4 months and assess the level change in speaking anxiety; this, unfortunately, meant that there were limited findings available on the effectiveness of the coping strategy used. If the reported techniques were classified based on Oxford's LLS (1990), compensation, metacognitive, affective, and social strategies were proved to be effective. However, the effectiveness of the relaxation technique, categorized under affective strategy, has yet to be affirmed due to the inconsistency of the findings.

\section{Discussion}

Overall, based on the findings, the included studies in this review highlighted several advisable considerations when applying different coping strategies. University students who (a) have an intermediate level of English language proficiency and high level of speaking anxiety could opt for compensation and metacognitive strategies; (b) have high levels of English language proficiency and speaking anxiety could opt for the affective strategy; and (c) have a high level of speaking anxiety and were exposed to full English medium instruction contexts could opt for social and memory strategies. The studies addressed in this review propose that the effectiveness of the cognitive strategy and its practicality in different groups of anxiety and language levels or types of English medium instruction contexts - partial or full - have yet to be assessed, as evidenced in Widhayanti's research (2018). Across different settings, the similar findings emphasized that university students who experienced speaking anxiety might use at least two coping strategies to reduce their fear, regardless of their language and anxiety levels. Even if only some aspects of learner characteristics were included across different research contexts, the findings could suggest pedagogical implications for university students who suffer from speaking anxiety in various settings.

Among the three parameters discussed - language proficiency level, full English medium instruction contexts, and high anxiety level - the included studies underscored types of English medium instruction contexts in determining suitable coping strategies to mitigate speaking anxiety. Most of the studies presupposed that university students, in their studies, fully practiced the target language when the courses taught were delivered in the English language. However, there might be situations where code-switching and the translation of concepts happened in lectures (Poon, 2013). Notably, the notion of willingness to communicate is a useful indicator to assess the effectiveness and frequency of strategies used under the influence of partial and full English medium instruction contexts. As MacIntyre and other researchers (1998) suggested, the "readiness to enter into discourse at a particular time with a specific person or persons, using an L2" (p. 547), could be influenced by social and personal factors. It results in different strategies used to cope with the fear when university students face speaking anxiety. When code-switching is tolerated, students use their first language in a situation where their mind goes blank during the presentation. In contrast, students seek social support or rehearse their script when they face the fear of speaking and only the English language is allowed for the presentation.

Furthermore, it was evident that most of the high achievers opted for the affective strategy to reduce their fear of speaking. It is explainable using Krashen's Affective Filter Hypothesis (1985), which proposes that affective filters associate negatively with speaking performance; in other words, if the affective filter is low, speaking performance is good and vice versa. Because high achievers did not face difficulties in using the English language, they chose the affective strategy to cope with anxiety-provoking situations. Lowering their affective filters facilitated the process of reducing their fear of speaking. Based on the findings, the assumption that some relaxation techniques, such as deep breathing, are easy to master would probably contribute to relatively high use. Thus, more sophisticated relaxation methods, such as progressive relaxation, should be introduced to enhance their effects on speaking anxiety dramatically. As demonstrated in the included studies that focused on the relationship between high levels of speaking anxiety and strategies used, it is no surprise that university students were the benefactors of applying compensation, memory, social, and metacognitive strategies because they 
addressed speaking anxiety with positive attitudes, making efforts to reduce their fear of speaking on stage. The affective strategy, on the other hand, shows different effects when students with high anxiety levels relied on it. This discrepancy could be attributed to the fact that most of them developed a behavior of learned helplessness. They gave up and accepted the situation because they believed it is tough to reduce the fear of speaking.

In continuation of the previous point, it is almost certain that the choice of coping strategies is explainable using Bandura's social cognitive theory that underpins self-regulated learning (Bembenutty et al., 2015). University students not only act on impulse and instinct but also self-organize and self-reflect on their actions based on the cognitive processes and social conditions they encounter. This explanation provided the foundation for Zimmerman's enduring concept of self-regulated learning (Salter, 2012). In line with Bandura's four-pillar principles of human agency-namely, intentionality, forethought, self-reactiveness, and self-reflectiveness - university students autonomously activate their cognition, affect, and behavior (Bembenutty et al., 2015) to reflect on outcomes, reach their goals, and regulate their real experiences of speaking anxiety. From here, with their competencies, self-beliefs, and outcome expectancies, they gain control over their experiences of dealing with speaking anxiety. Therefore, students would be able to analyze their strengths and weaknesses, find solutions for their problems, and, finally, boost their confidence level when they monitor their progress of mitigating their fear of being on stage.

\section{Implications for Future Research}

The reviewed studies propose that university students with different personal and social factors, such as language proficiency level, speaking anxiety level, and English medium instruction contexts, use different strategies to reduce their fear of speaking in front of others. Nonetheless, the complexities of university students' strategy use are not fully understood because additional parameters have yet to be considered. Despite the relatively robust findings, no research has been found that devised a systematic and practicable set of coping strategies. Little is also known about the actual use of coping strategies to reduce students' fear, before and after a presentation. Notably, more longitudinal studies should be undertaken to substantiate observations, widen the body of qualitative research available, and increase the authenticity of the findings. In an era of the fourth industrial globalization, it is incumbent on higher-learning institutions to impart soft skills that university students need for the future workforce. As a result, additional research is required to investigate how university students cope with their fear of speaking under different circumstances-from formal to informal.

Although this review has investigated university students' use of strategies to cope with their speaking anxiety, the existing studies have a few limitations. As Horwitz (2001) noted, state anxiety differs from trait anxiety in that the former suggests a short experience of anxiety whereas the latter results from individual factors-i.e., personality - that could cause a person to be anxious anytime and anywhere. Therefore, university students who have trait anxiety will quickly feel more anxious than those who have state anxiety. Due to this personality factor, their degree of speaking anxiety is more robust, and the listed coping strategies in this review would wane. In conclusion, further research to examine the effect of coping strategies used to counter the two types of speaking anxiety would undeniably extend the growing body of literature that encompasses the practicality of listed coping strategies. This line of research would provide meaningful insights to lecturers in better understanding how stressed university students are when they face speaking anxiety, while at the same time refining a variety of pedagogical methods to lower the "psychological" barriers of speaking.

\section{References}

Allen, M., Hunter, J. E., \& Donohue, W. A. (1989). Meta-analysis of self-report data on the effectiveness of public speaking anxiety treatment techniques. Communication Education, 38(1), 54-76. https://doi.org/10.1080/03634528909378740

Anandari, C. L. (2015). Indonesian EFL students' anxiety in speech production: Possible causes and remedy. TEFLIN Journal, 26(1), 1-16. https://doi.org/10.15639/teflinjournal.v26i1/1-16

Bembenutty, H., White, M., \& Velez, M. (2015). Developing self-regulation of learning and teaching skills among teacher candidates. Springer Dordrecht Heidelberg. https://doi.org/10.1007/978-94-017-9950-8

Benson, P. (1997). The philosophy and politics of learner autonomy. In P. Benson \& P. Voller (Eds.), Autonomy and independence in language learning (pp. 18-34). Longman. https://doi.org/10.4324/9781315842172-3

Bodie, G. D. (2010). A racing heart, rattling knees, and ruminative thoughts: Defining, explaining, and treating public speaking anxiety. Communication Education, 59(1), 70-105. https://doi.org/10.1080/03634520903443849 
Chou, M. H. (2018). Speaking anxiety and strategy use for learning English as a foreign language in full and partial English-medium instruction contexts. Tesol Quarterly, 52(3), 611-633. https://doi.org/10.1002/tesq.455

Cohen, Y., \& Norst, M. J. (1989). Fear, dependence and loss of self-esteem: Affective barriers in second language learning among adults. RELC Journal, 20(2), 61-77. https://doi.org/10.1177/003368828902000206

El-Sakka, S. M. F. (2016). Self-regulated strategy instruction for developing speaking proficiency and reducing speaking anxiety of Egyptian university students. English Language Teaching, 9(12), 22-33. https://doi.org/10.5539/elt.v9n12p22

Furmark, T. (2002). Social phobia: Overview of community surveys. Acta Psychiatr Scand, 105, 84-93. https://doi.org/10.1034/j.1600-0447.2002.1r103.x

Genc, G., Kulusakli, E., \& Aydin, S. (2016). Foreign language speaking anxiety and anxiety coping strategies employed by Turkish EFL learners. Proceedings of 9th Annual International Conference of Education, Research and Innovation, 417-423. https://doi.org/10.21125/iceri.2016.1105

He, D. (2017). How to cope with foreign language speaking anxiety effectively? The case of university students in China. Electronic Journal of Foreign Language Teaching, 14(2), 159-174. Retrieved from https://e-flt.nus.edu.sg/

Horwitz, E. (2001). Language anxiety and achievement. Annual Review of Applied Linguistics, 21(1), 112-126. https://doi.org/10.1017/S0267190501000071

Horwitz, E. K., Horwitz, M. B., \& Cope, J. (1986). Foreign language classroom anxiety. The Modern Language Journal, 70(2), 125-132. https://doi.org/10.1111/j.1540-4781.1986.tb05256.x

Jaafar, S. S. (2020, June 15). Malaysia's April unemployment spikes to 5\%, the highest in 30 years. The Edge Markets.

Retrieved

from https://www.theedgemarkets.com/article/malaysia-unemployment-rate-spiked-5-april

Kondo, D. S., \& Yang, Y. L. (2004). Strategies for coping with language anxiety: The case of students of English in Japan. ELT Journal, 58(3), 258-265. http://doi.org/10.1093/elt/58.3.258

Krashen, S. D. (1985). The input hypothesis: Issues and implications. Longman.

Kushner, M. (2004). Public speaking for dummies. John Wiley \& Sons Inc.

Lucas, J. (1984). Communication apprehension in the ESL classroom: Getting our students to talk. Foreign Language Annals, 17(6), 593-598. https://doi.org/10.1111/j.1944-9720.1984.tb01748.x

MacIntyre, P. D., Dornyei, Z., Clement, R., \& Noels, K. A. (1998). Conceptualizing willingness to communicate in a L2: A situational model of L2 confidence and affiliation. Modern Language Journal, 82(4), 545-562. https://doi.org/10.2307/330224

McCroskey, J. C. (1972). The implementation of a large-scale program of systematic desensitization for communication apprehension. Speech Teacher, 21, 255-264. https://doi.org/10.1080/03634527209377961

Mehar Singh, M. K., \& Chuah, J. S. C. (2012). Manufacturing industry employers' perception of graduates' English language skills proficiency. International Journal of Applied Linguistics \& English Literature, 1(4), 114-124. https://doi.org/10.7575/ijalel.v.1n.4p.114

Moher, D., Liberati, A., Tetzlaff, J., \& Altman, D. G. (2010). Preferred reporting items for systematic reviews and meta-analyses: The PRISMA statement. International Journal of Surgery, 8(5), 336-341. https://doi.org/10.1136/bmj.b2535

Murase, F. (2015). Measuring language learner autonomy: Problems and possibilities. In C. Everhard \& L. Murphy (Eds.), Assessment and autonomy in language learning (pp. 35-63). Palgrave Macmillan. https://doi.org/10.1057/9781137414380_3

North, M., \& Rives, J. (2001). Virtual reality therapy in aid of public speaking. International Journal of Virtual Reality, 3, 2-7.

Oxford, R. (1990). Language learning strategies: What every teacher should know. Newbury House Publishers.

Oxford, R. L. (2003). Toward a more systematic model of L2 learner autonomy. In D. Palfreyman \& R. C. Smith (Eds.), Learner autonomy across cultures: Language education perspectives (pp. 75-91). Palgrave Macmillan. https://doi.org/10.1057/9780230504684 5 
Ozturk, G., \& Gurbuz, N. (2014). Speaking anxiety among Turkish EFL learners: The case at a state university. Journal of Language and Linguistic Studies, 10(1), 1-17.

Pandey, M., \& Pandey, P. (2014). Better English for better employment opportunities. International Journal of Multidisciplinary Approach and Studies, 1(4), 93-100.

Pappamihiel, N. E. (2002). English as a second language students and English language anxiety: Issues in the mainstream classroom. ProQuest Education Journal, 36(3), 327-355.

Poon, A. Y. K. (2013). Will the new fine-tuning medium-of-instruction policy alleviate the threats of dominance of English-medium instruction in Hong Kong? Current Issues in Language Planning, 14, 34-51. https://doi.org/10.1080/14664208.2013.791223

Pratama, R., Ikhsanudin, I., \& Salam, U. (2018). A student's strategies to overcome speaking anxiety in public speaking class. Jurnal Pendidikan dan Pembelajaran Khatulistiwa, 7(9), 1-8.

Rafada, S. H., \& Madini, A. A. (2017). Effective solutions for reducing Saudi learners' speaking anxiety in EFL classrooms. Arab World English Journal, 8(2), 308-322. https://doi.org/10.24093/awej/vol8no2.22

Raja, F. (2017). Anxiety level in students of public speaking: Causes and remedies. Journal of Education and Educational Development, 4(1), 94-110. https://doi.org/10.22555/joeed.v4i1.1001

Roever, L. (2015). Critical appraisal of a questionnaire study. Evidence Based Medicine and Practice, 1(2), 1-2. https://doi.org/10.4172/2471-9919.1000e110

Ruscio, A. M., Brown, T. A., Chiu, W. T., Sareen, J., Stein, M. B., \& Kessler, R. C. (2008). Social fears and social phobia in the USA: Results from the national comorbidity survey replication. Psychological Medicine, 38(1), 15-28. https://doi.org/10.1017/S0033291707001699

Sachdeva, M. S. (2007). Teaching English as a foreign language. Tandon Publications.

Salter, P. (2012, December 2). Developing self-regulated learning in secondary schools [Paper presentation]. Joint AARE APERA International Conference, Sydney. Retrieved from https://www.aare.edu.au/publications/aare-conference-papers/show/7086/developing-self-regulated-learners -in-secondary-schools

Schneier, F. R., Heckelman, L. R., Garfinkel, R., Campeas, R., Fallon, B. A., Gitow, A., Street, L., Del Bene, D., \& Liebowitz, M. R. (1994). Functional impairment in social phobia. The Journal of Clinical Psychiatry, 55(8), 322-331.

Stein, M. B., Walker, J. R., \& Forde, D. R. (1994). Setting diagnostic thresholds for social phobia: Considerations from a community survey of social anxiety. American Journal of Psychiatry, 151, 408-412. https://doi.org/10.1176/ajp.151.3.408

Whitworth, R. H., \& Cochran, C. (1996). Evaluation of integrated versus unitary treatments for reducing public speaking anxiety. Communication Education, 45, 306-314. https://doi.org/10.1080/03634529609379060

Widhayanti, Z. (2018). English department students' learning strategies to overcome speaking anxiety. RETAIN, 6(2), 60-67.

Yasuda, T., \& Nabei, L. (2018). Effects of coping strategies on language anxiety of Japanese EFL learners: Investigating willingness to communicate. Journal of Language Teaching and Research, 9(5), 905-915. https://doi.org/10.17507/jltr.0905.03

Young, D. J. (1992). Language anxiety from the foreign language specialist's perspective: Interviews with Krashen, Omaggio Hadley, Terrell, and Rardin. Foreign Language Annals, 25(2), 157-172. https://doi.org/10.1111/j.1944-9720.1992.tb00524.x

\section{Copyrights}

Copyright for this article is retained by the author(s), with first publication rights granted to the journal.

This is an open-access article distributed under the terms and conditions of the Creative Commons Attribution license (http://creativecommons.org/licenses/by/4.0/). 